\title{
Enzalutamide: A New Hormonal Treatment for Triple-Negative Breast Cancer?
}

Francesco Caiazza*,Alyson Murray*, Naoise Synnott, Steven Madden, John Crown, Michael J Duffy

School of Medicine and Medical Sciences, University College Dublin

St.Vincents University Hospital, Elm Park, Dublin 4, Ireland

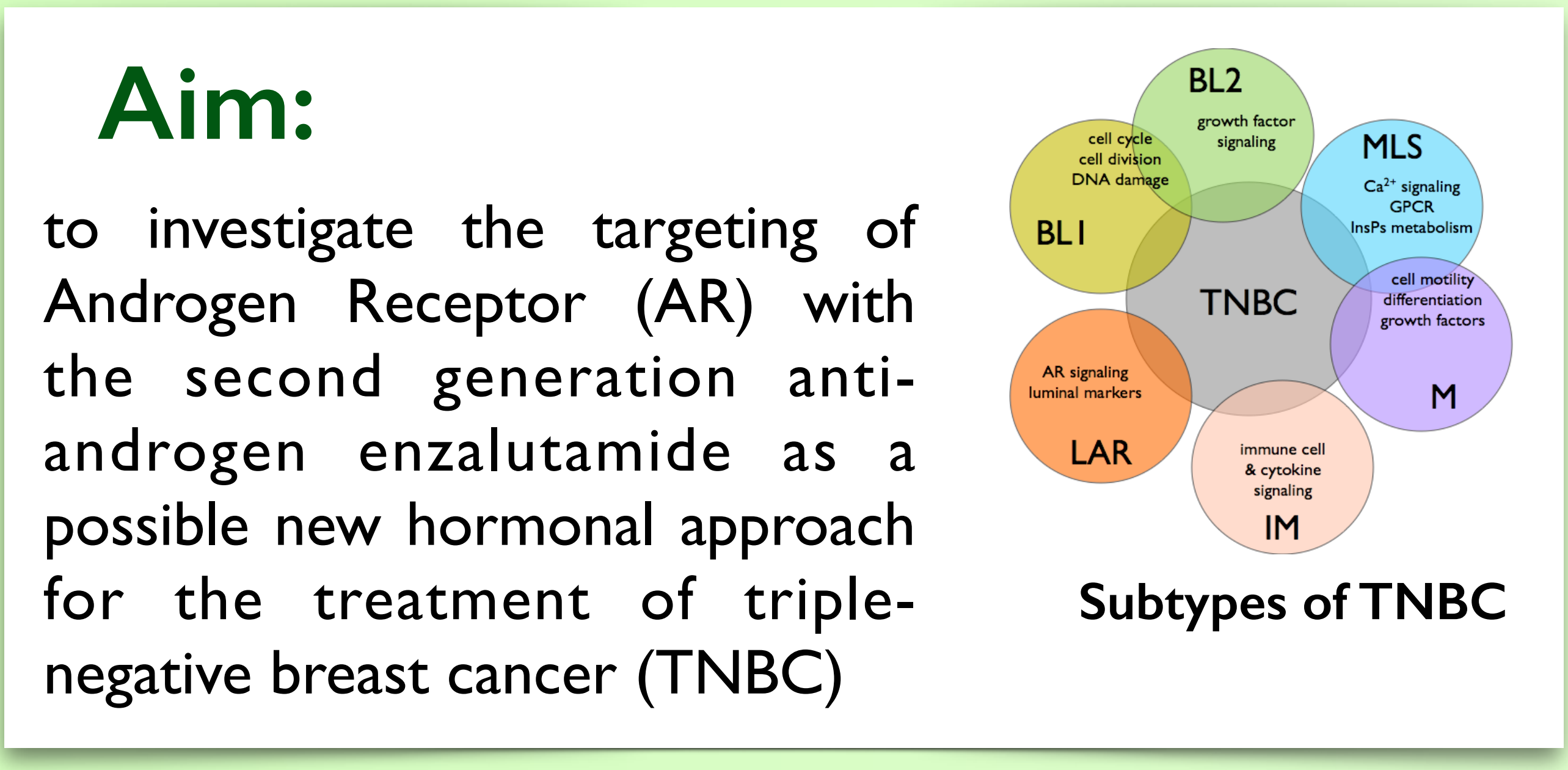

1

Effect of enzalutamide in $B C$ cells is related to $A R$ protein expression

The effect of enzalutamide on clonogenic growth of II breast cancer cell lines (8 TNBC, 3 non TN) is summarized in (A). Sensitivity to enzalutamide was widely variable, with IC 50 values ranging from $4 \mu \mathrm{M}$ to 政 HCCI 937 cells.

The response to enzalutamide was unrelated to TN status (B) but was cell line-dependent.WB and ELISA analysis of AR expression (C) revealed a highly significant correlation between the level
sensitivity to enzalutamide $(r=-0.803, p=0.003)$ (D).
A

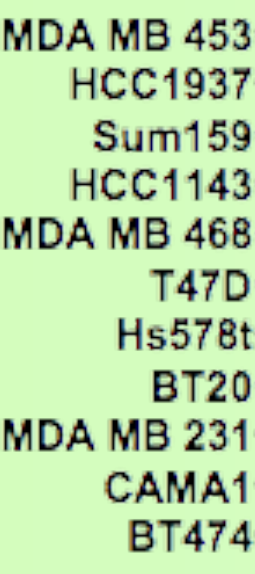

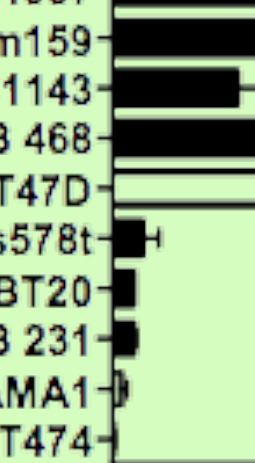

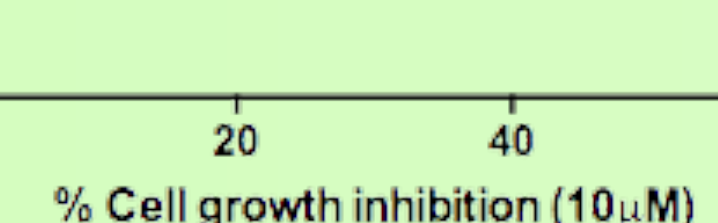
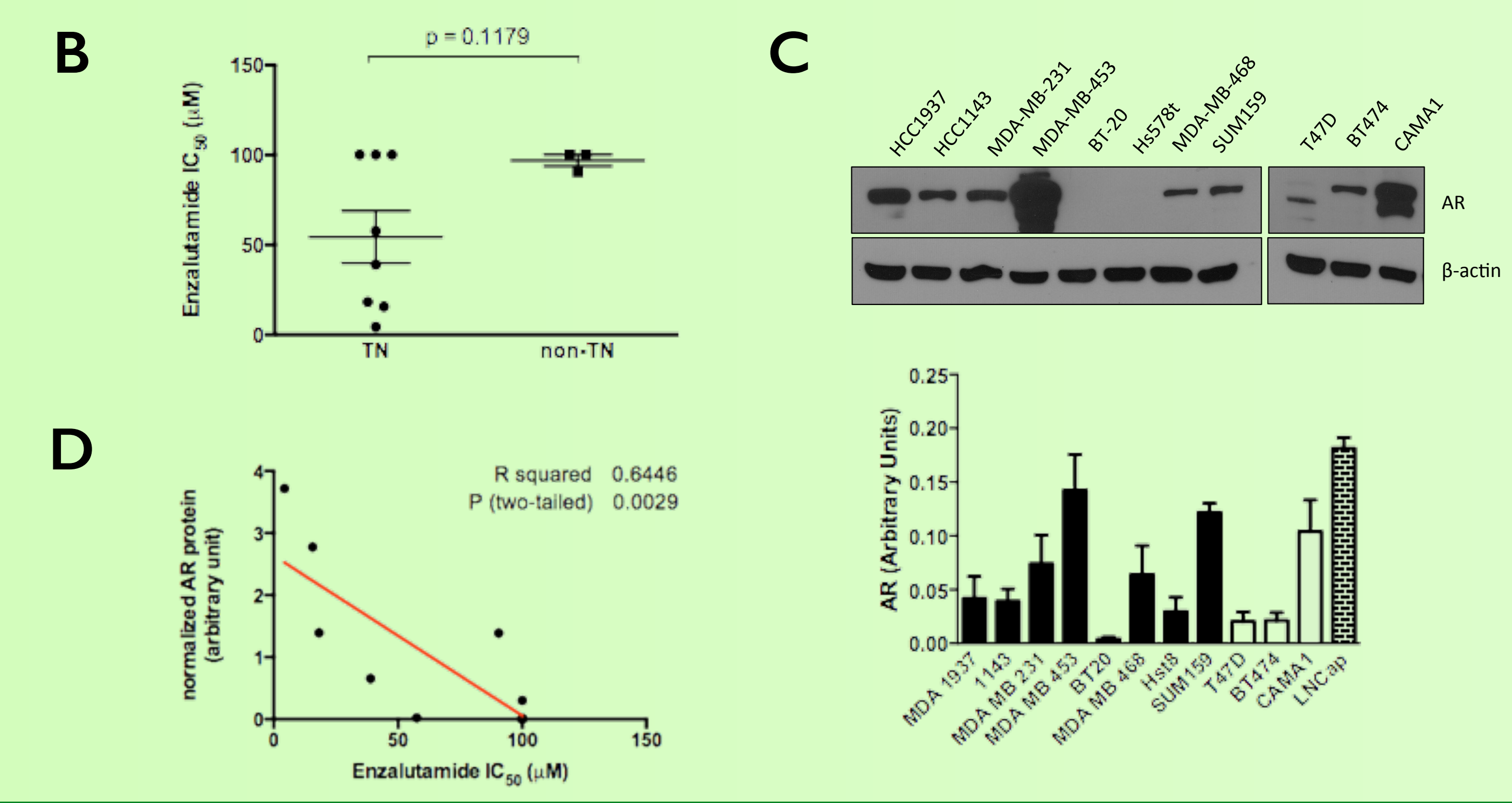

Arish Cancer
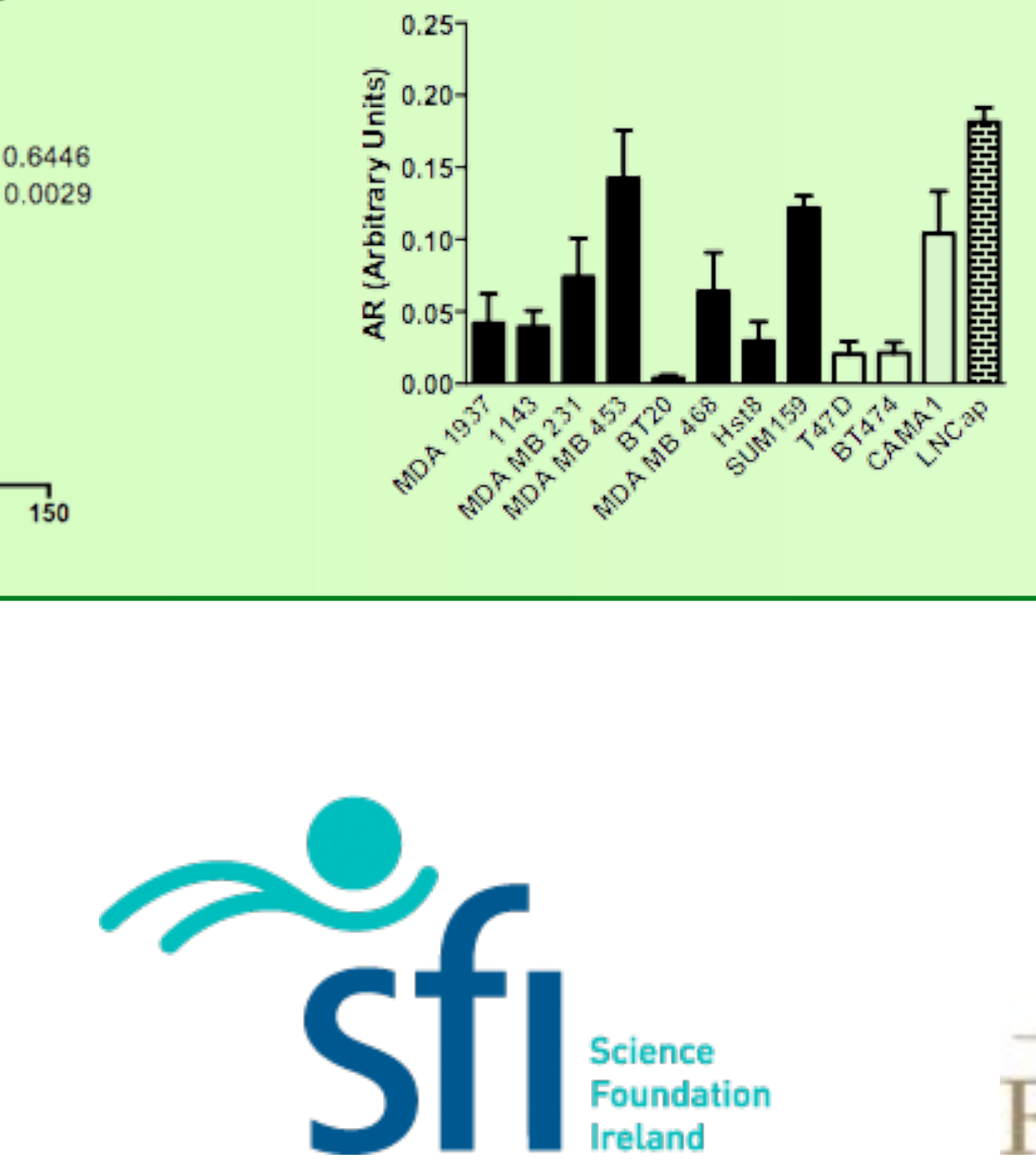

A

B
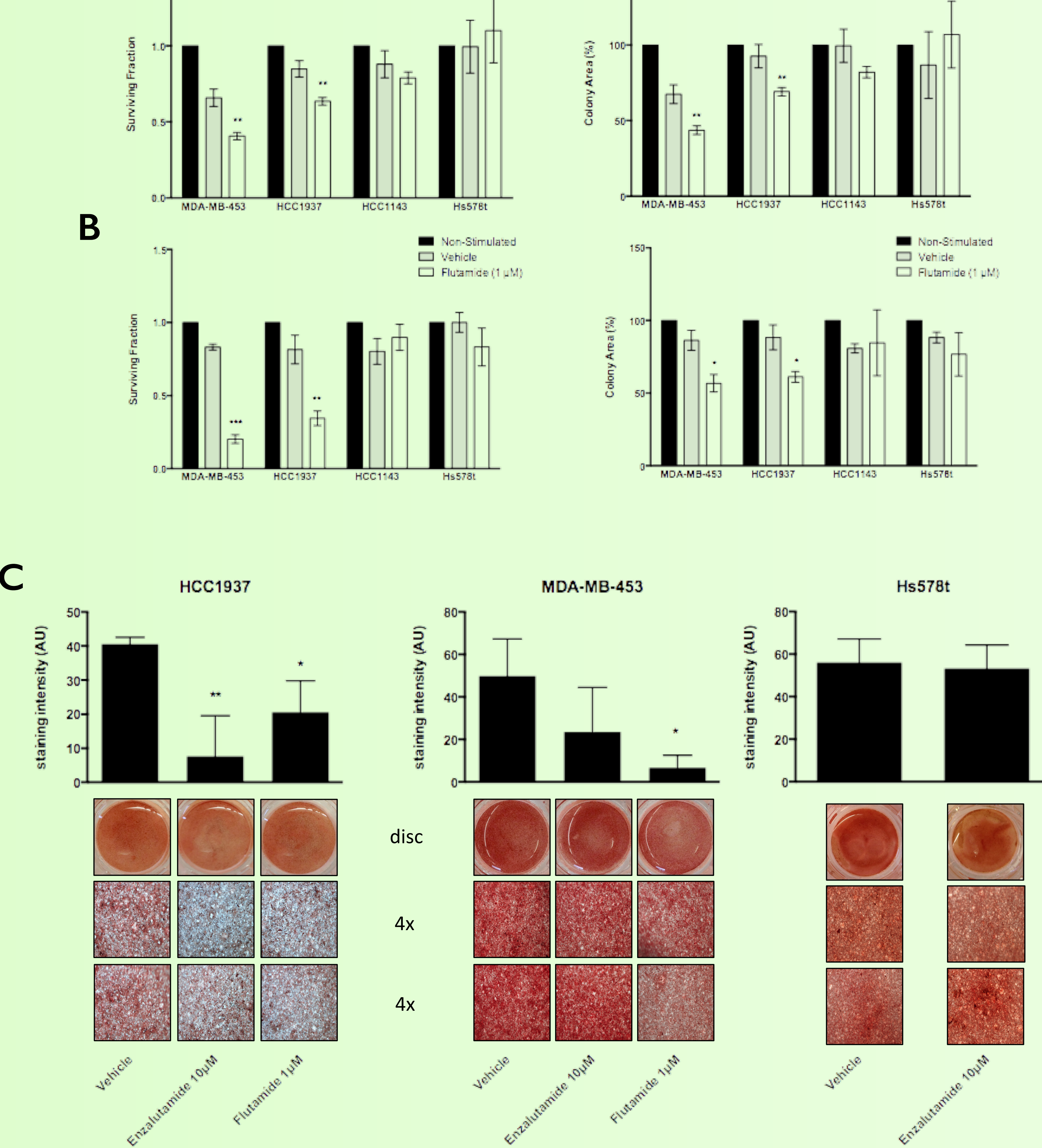

2
(A) Enzalutamide reduced clonogenic potential as mess 政 lines expressing high levels of AR (MDA-MB-453 and HCC 1937). In contrast, there was no significant effect on growth in the cell lines with low (HCCI143 cells) or no detectable (Hs578t cells) AR he effect of the two inhibitors was cell linethamide and enzalutamide reducing the growth ( $\mathrm{MCC} 937$ cells, while only flutamide significantly reduced growth

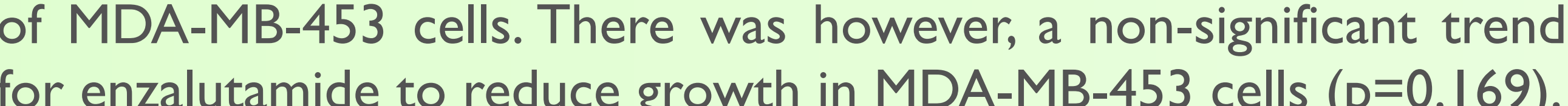

3

Enzalutamide reduced cell migration and invasion in the 3 AR-positive cells lines, i.e., in MDA-MB-453 (A), HCC 1937 No change in migration or invasion was seen in the ARnegative cell line Hs578t (D). Flutamide also had similar effects (data not shown).

\section{4}

Prognostic effect of AR in TNBC

Prognostic value of AR expression in 2091 database, using $O S$ as the survivat ent-park and "low" as the expression cut-off. KaplanMeyer estimates for (A) unselected patients $(\mathrm{n}=2091, \mathrm{HR}=0.706, \mathrm{p}=1.928 \times 10-4)$, (B) $H R=0.49, p=1.37 \times 10-3)$, or $(C)$ (C) $(n=812$, basel subtype $(n=273, H R=1.709, P=0.039)$. AR lacked a prognostic impact in the luminal $B$ and HER2-positive subtypes (data not
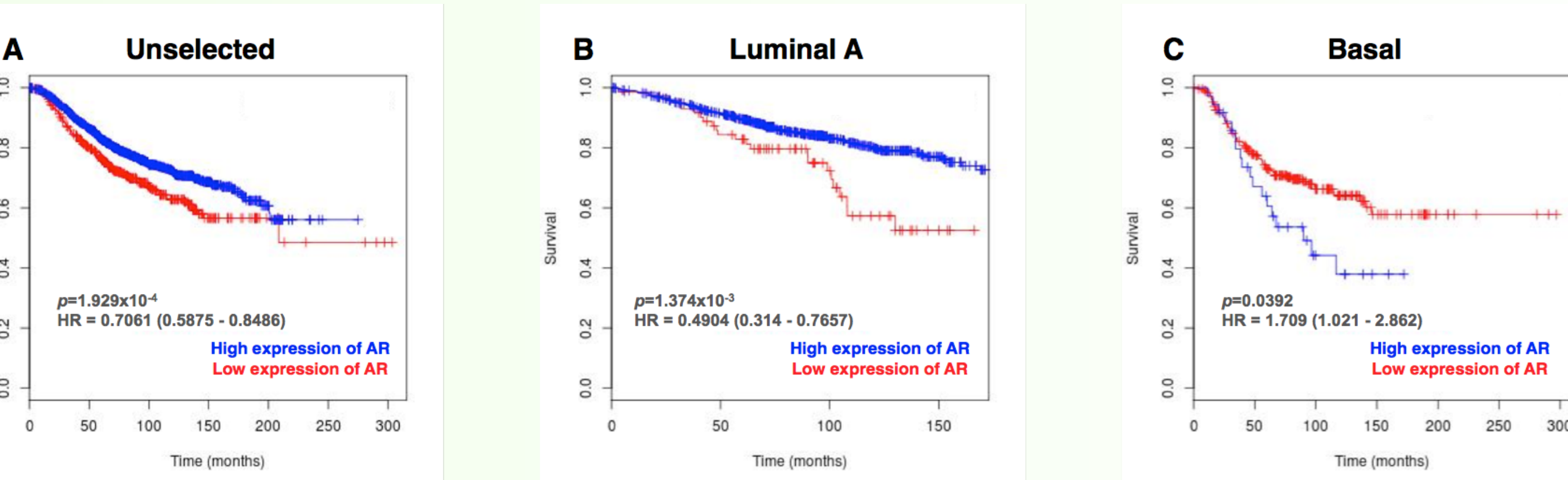

5 Effects of enzalutamide in combination strategies

When cells were treated with enzalutamide in combination with standard chemotherapeutic cogs, the addion of Doxorubicin enhanced mhibited the growth of the non-453 and also cell line No effect was found with cis-platinum carbo-platinum or 5-FU.

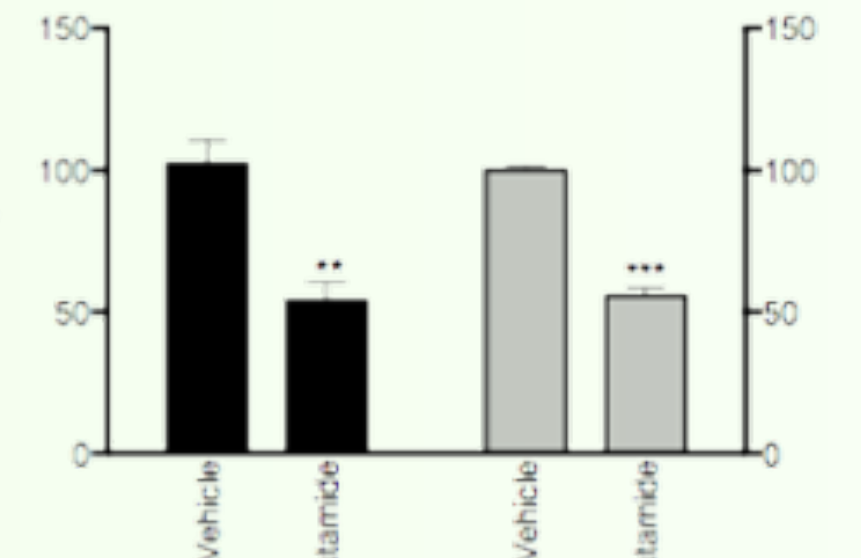

HCC1143

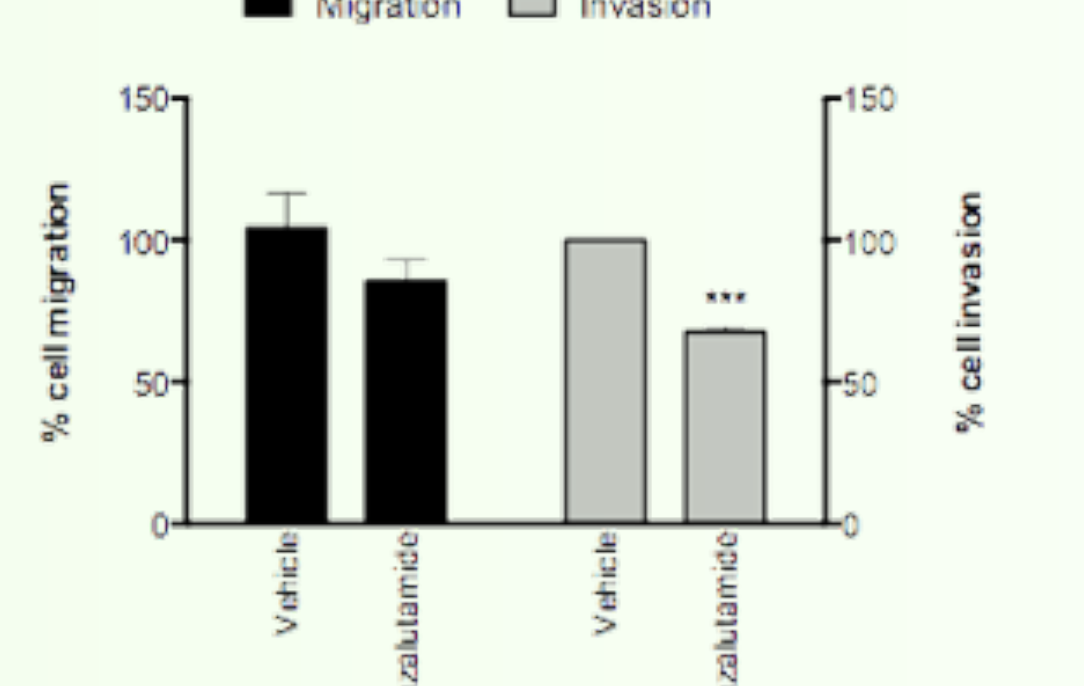

Msasion

II

\section{Conclusions:}

We have shown that two structurally different antiandrogens can inhibit cell growth, invasion and migration on paing wich TNBC Since antiandrogens are already widely used to treat metastatic prostate cancer repurposing them for use in TNBC would be expected to proceed rapidly.
\#ASCOI 5

@francescocay *joint first authors:

francesco.caiazza@gmail.com alyson.murray@ucd.ie 